\title{
SCIENTIFIC REP RTS OPEN Author Correction: Cathelicidin-OA1, a novel antioxidant peptide identified from an amphibian, accelerates skin wound healing
}

Xiaoqing $\mathrm{Cao}^{1}$, Ying Wang ${ }^{2}$, Chunyun $\mathrm{Wu}^{3}$, Xiaojie $\mathrm{Li}^{4}$, Zhe Fu ${ }^{3}$, Meifeng Yang ${ }^{3}$, Wenxin Bian ${ }^{3}$, Siyuan Wang ${ }^{2}$, Yongli Song ${ }^{3}$, Jing Tang ${ }^{4} \&$ Xinwang Yang ${ }^{3}$

Correction to: Scientific Reports https://doi.org/10.1038/s41598-018-19486-9, published online 17 January 2018

This Article contains errors. Figure 8 was misassembled during the preparation of the manuscript: incorrect images were used for panel $8 \mathrm{C}$, and for the vehicle image in panel $8 \mathrm{E}$. The correct Figure 8 appears below as Figure 1.

The conclusions of the Article are unaffected by this correction.

\footnotetext{
${ }^{1}$ Department of Pathology, Faculty of Basic Medical Science, Kunming Medical University, Kunming, 650500, Yunnan, China. ${ }^{2}$ Key Laboratory of Chemistry in Ethnic Medicine Resource, State Ethnic Affairs Commission \& Ministry of Education, School of Ethnomedicine and Ethnopharmacy, Yunnan Minzu University, Kunming, 650500, Yunnan, China. ${ }^{3}$ Department of Anatomy and Histology \& Embryology, Faculty of Basic Medical Science, Kunming Medical University, Kunming, 650500, Yunnan, China. ${ }^{4}$ Department of Biochemistry and Molecular Biology, Faculty of Basic Medical Science, Kunming Medical University, Kunming, 650500, Yunnan, China. Xiaoqing Cao, Ying Wang and Chunyun Wu contributed equally. Correspondence and requests for materials should be addressed to J.T. (email: gracett916@163.com)orX.Y. (email:yangxinwanghp@163.com)
} 
A

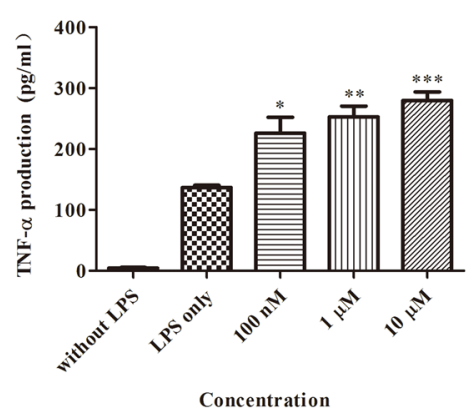

C

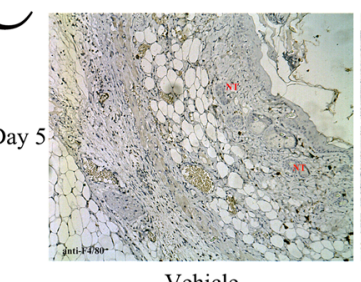

Vehicle

$\mathrm{E}$

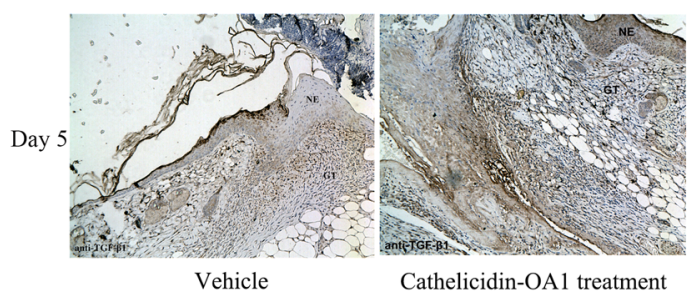

$\mathrm{B}$

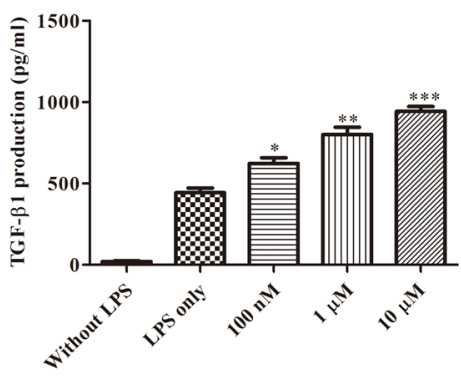

Concentration
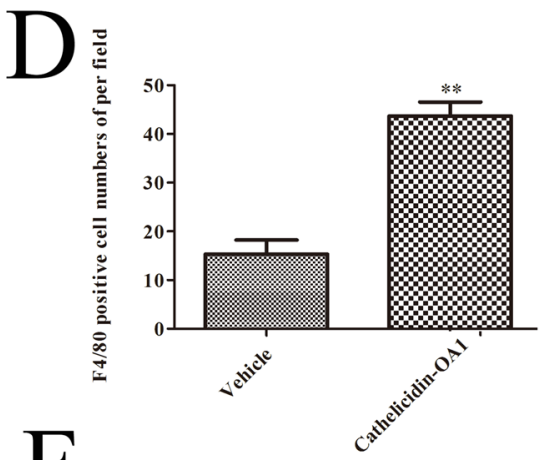

$\mathrm{F}$

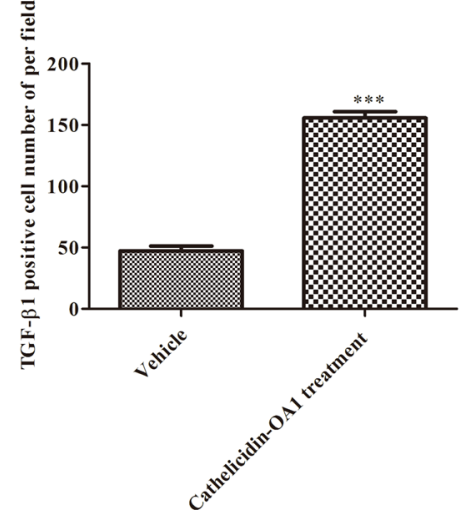

Figure 1. Cathelicidin-OA1 promoted the secretion of TNF- $\alpha$ and TGF- $\beta$, macrophages recruitment, TGF- $\beta$ expression. (A,B) THP- 1 cells were stimulated by LPS to secrete TNF- $\alpha$ and TGF- $\beta 1$. Incubation with cathelicidin-OA1 at different concentrations resulted in the dose-dependent increase in TNF- $\alpha$ and TGF- $\beta 1$ secretion. ${ }^{*} \mathrm{P}<0.05, * * \mathrm{P}<0.01$, and ${ }^{* * *} \mathrm{P}<0.0001$ indicate significantly different from the negative control (Student's $t$-test). Data are mean values of three independent experiments performed in triplicate. (C,E) Immunohistochemical results for anti-F4/80 and TGF- $\beta 1$. (D,F) F4/80 or TGF- $\beta 1$ positive cell numbers per high power field were significantly different between cathelicidin-OA1 treatment and the control. ${ }^{* * \mathrm{P}}<0.01$ and $* * * \mathrm{P}<0.0001$. Data are mean values of three independent experiments performed in triplicate and six different fields for each section $(\times 100)$.

(i) Open Access This article is licensed under a Creative Commons Attribution 4.0 International License, which permits use, sharing, adaptation, distribution and reproduction in any medium or format, as long as you give appropriate credit to the original author(s) and the source, provide a link to the Creative Commons license, and indicate if changes were made. The images or other third party material in this article are included in the article's Creative Commons license, unless indicated otherwise in a credit line to the material. If material is not included in the article's Creative Commons license and your intended use is not permitted by statutory regulation or exceeds the permitted use, you will need to obtain permission directly from the copyright holder. To view a copy of this license, visit http://creativecommons.org/licenses/by/4.0/.

(c) The Author(s) 2018 